E2-2006-183

M. Timko ${ }^{1}$, P. Kopčanský ${ }^{1}$, M. Repašan ${ }^{1}$, M. Koneracká ${ }^{1}$, M. Hnatič ${ }^{1}$, A. Džarová ${ }^{1}$, J. Štelina ${ }^{2}$, C. Musil ${ }^{2}$, E. Ayrjan ${ }^{3}$

\title{
STRUCTURALIZATION INDUCED BY PHOTOTHERMAL EFFECT IN MAGNETIC FLUID FILM
}

Presented at the International Conference «Mathematical Modeling and Computational Physics 2006», High Tatra Mountains, Slovakia, August 28September 1, 2006.

\footnotetext{
${ }^{1}$ Institute of Experimental Physics SAS, Watsonova 47, 04001 Košice, Slovakia

${ }^{2}$ Department of Physics, University of Žilina, Univerzitná 1, 01026 Žilina, Slovakia

${ }^{3}$ Joint Institute for Nuclear Research, Dubna
} 
Тимко М. и др.

Структурализация, индуцированная фототермальным эффектом,

в пленке из магнитной жидкости

Структурализация магнитных частиц после облучения лазерным лучом была экспериментально наблюдаема в двух видах магнитной жидкости. Основой первой является минеральное масло, содержащее частицы из магнетита, покрытое одним слоем, а второй - керосин, стерильно стабилизированный двойным слоем, состоящим из масляной и додецилбензенсульфатной кислоты. Данная статья представляет детальное теоретическое описание термодиффузионного процесса в магнитных жидкостях, моделирование структурализации в магнитной жидкости с отрицательной константой Сорета и подтверждение отрицательного значения этой константы для второго типа магнитной жидкости.

Работа выполнена в Лаборатории информационных технологий ОИЯИ.

Препринт Объединенного института ядерных исследований. Дубна, 2006

Timko M. et al.

Structuralization Induced by Photothermal Effect

in Magnetic Fluid Film

The structuralization of magnetic particles after illumination was experimentally observed in two types of a magnetic fluid: magnetic fluid based on mineral oil with the magnetite particles covered by mono-layer surfactant, and kerosene-based magnetic fluid sterically stabilized by a double-layer consisting of oleic acid and dodecylbenzensulphonic acid (DBS). This contribution presents a detailed theoretical description of the thermodiffusion process in magnetic fluids, simulation of the structuralization in magnetic fluid with a negative Soret constant and confirmaton of the negative value of this constant for a kerosene-based magnetic fluid.

The investigation has been performed at the Laboratory of Information Technologies, JINR. 


\section{INTRODUCTION}

The formation of the magnetite nanoparticle structuralization in magnetic fluids is observed as a consequence of concentration and thermal diffusion of nanoparticles. The temperature gradients can arise due to light-absorption on the accidental concentration fluctuations of particles or on the well-defined geometric structure such as a concentration diffraction grating. The method is based on Forced Rayleigh Scattering (FRS) experiment, in which a diffraction concentration grating is created in a thin sample of a colloidal fluid due to the periodic spatial temperature modulation. From the time dependence of the grating decay it is possible to determine a sign of thermo-diffusion Soret coefficient $S$. The lightinduced heating of fluids can give rise to interesting phenomena, which depend upon the illumination character and the type of illuminated fluid. In colloidal fluids a temperature gradient invokes a flow of colloidal particles - thermodiffusion. This process is characterized by Soret constant $S=D_{T} / D_{\mathrm{dif}}, D_{\mathrm{dif}}$ is particle translation diffusion coefficient and $D_{T}$ is a thermal diffusion coefficient.

An interesting feature of thermodiffusion in magnetic fluids is that positive $\left(S_{T}>0\right)$ or negative $\left(S_{T}<0\right)$ Soret effect can be observed, depending on the type of the studied fluid. If a magnetic fluid with the positive Soret constant is illuminated, the flow of colloidal particles against the temperature gradient direction is present, i.e., the particles escape from the beam axis. In a magnetic fluid with negative Soret constant, the directions of the concentration flow and the temperature gradient are identical, i. e., the local temperature increase attracts the absorbing particles into a warmer region. In such a magnetic fluid an interesting phenomenon can be observed - the creation of a structure with «islands» of enhanced concentration, known as the light-induced structuralization. Different techniques have been used to determine the Soret constant, particularly based on the thermodiffusion columns [1] or on the Forced Rayleigh Scattering (FRS) [2]. The $Z$-scan technique [3], commonly employed to investigate the nonlinear properties of a medium, allowed one to make a classification of magnetic fluids based on the stabilization type, surfactant, carrier liquid and the material of colloidal magnetic particles. The Forced Rayleigh Scattering method consists in the creation of a concentration optical grating in magnetic fluid, due to its interaction with the interference field of two laser beams. The light passing through the sample diffracts on created concentration grating, thus the effect is known as self-diffraction, too. 
In our previous work [4] we tried to give a more detailed theoretical description of the thermodiffusion process in magnetic fluids, now the aim is to simulate the structuralization in magnetic fluid with negative Soret constant and to confirm the negative value of this constant for a kerosene-based magnetic fluid.

\section{THEORY}

Our theoretical description of the light-induced thermodiffusion in a magnetic fluid was based on the analysis of the created temperature distribution and its influence upon the distribution of colloidal magnetic particles. A thin sample (plane $x y$ ) of the magnetic fluid was supposed to be illuminated with intensity harmonically changing in the direction normal to the light propagation direction. The formulas for the temperature and concentration modulations were found [4], which could be used to describe the phenomena observed in magnetic fluids at intensive illumination. At such an illumination the large changes of the particle concentration are present, which influence the light absorption coefficient and this way also the heating distribution. Thus, the formula for the amplitude of the temperature distribution, found in [4], had to include the space and time dependence of the colloidal particles concentration $n(x, y, t)$

$$
T_{0}=\frac{I_{0} \alpha_{0}}{2\left(\lambda \Omega^{2}+\lambda^{\prime}\right)} n(x, y, t),
$$

here $I_{0}$ is the amplitude of the space dependence of the illumination, varying with the period $2 \pi / \Omega$ in the $x$ direction, $\alpha_{0}$ denotes the absorption coefficient corresponding to the unit volume concentration, $\lambda$ is the thermal conductivity coefficient of studied fluid and $\lambda^{\prime}$ is the heat outlet coefficient (supposed to be the same in each point of the sample). Here it should be mentioned, that Eq. (1) is valid both for the periodic heating distribution caused by periodic illumination and for periodic heating due to the periodic distribution of the particle concentration. The formula describing the development of the possible periodic in space (harmonic) inhomogenity of the magnetic particle concentration was then found in form

$$
\frac{\partial n}{\partial t}=D_{\mathrm{dif}}\left(1+S K n I_{0}\right)\left(\frac{\partial^{2} n}{\partial x^{2}}+\frac{\partial^{2} n}{\partial y^{2}}\right)
$$

In this equation the substitution $K=\alpha_{0} 2\left(\lambda \Omega^{2}+\lambda^{\prime}\right)$ was used. On the ground of it any distribution of the particle concentration can be expressed by the Fourier integral (sum of harmonic dependencies with different space frequencies $\Omega_{m}$, using Eq. (2) the development of any fluctuation could be predicted). However, concentration $n$ should then represent the corresponding Fourier component $\mathrm{nm}$, and the value of $K$ would be different for individual Fourier components. The 
non-linear equation Eq. (2) is useful for a qualitative description of the structuralization process connected with illumination of the magnetic liquid with a negative Soret constant $S$. If the Soret constant fulfils the inequality

$$
S<-\frac{1}{K n_{0} I_{0}}
$$

( $n=n_{0}+\delta n$ and $n_{0}$ means concentration), then an accidentally occurred concentration maximum will increase and a minimum - decrease. In other words, if a sample of magnetic fluid with the negative Soret constant is illuminated, then, after the intensity of the light reaches the value

$$
I_{0}^{c}=1 /\left(K n_{0}|S|\right),
$$

at which the inequality (3) is fulfilled, a structure with islands of enhanced concentration will arise. It is because an instant fluctuation (which is always present) is amplified. A simulation of the development of such a structure (structuralization) in magnetic fluid with negative Soret constant was made by numerical integration of Eq. (2). Figure 1 illustrates the state of a thin magnetic fluid sample with the developed concentration structure after the intensity reached the critical value $I_{0}^{c}$. It is well known that if only a stationary concentration gradient is present in the sample, the particle diffusion flux is oriented into the places with lower concentration and after some time the equilibrium state occurs [5-7].

If the temperature gradient is also present, particles will diffuse from higher to lower temperature places when $S>0$. In the case when $S<0$, the thermodiffusion flux may cause the diffusion of the particles into the places with higher temperature (Fig. 2). In the sample which is illuminated by an external homogeneous light field the structuralization will arise, if the stochastic inhomogeneities

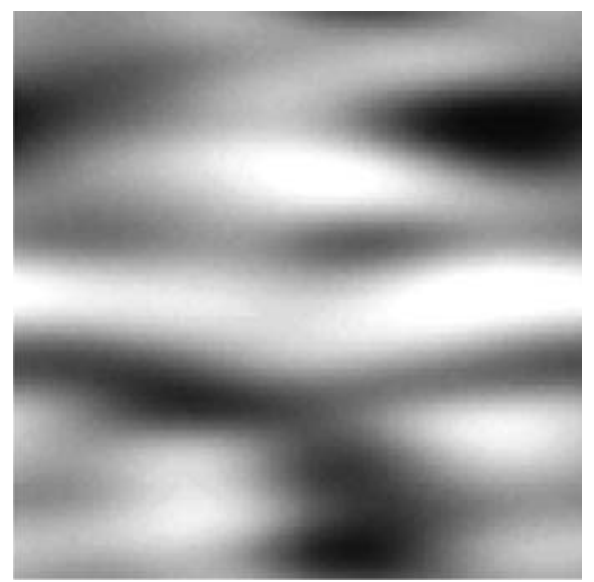

Fig. 1. The illustration of the developed structuralization in magnetic fluid with $S<0$ 

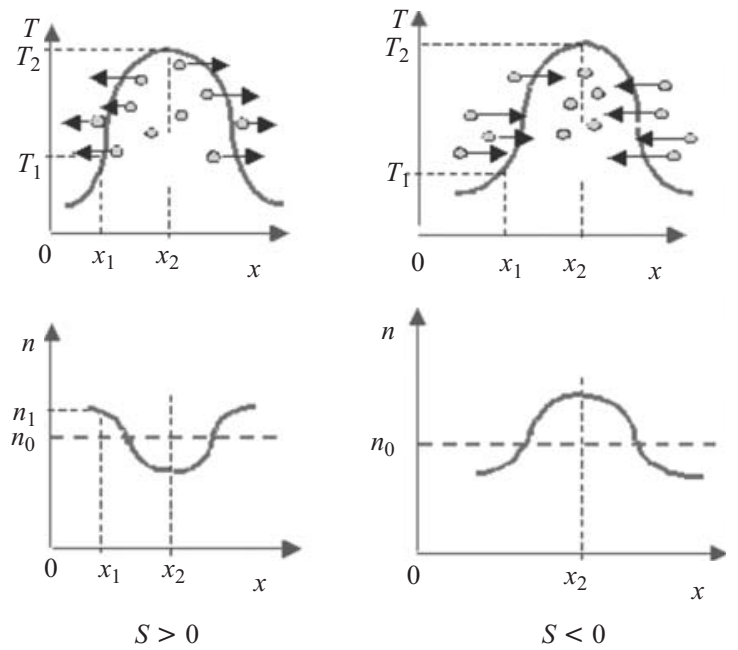

Fig. 2. The illustration of particle thermodiffusion in disperse fluid with positive $S>0$ and negative $S<0$ thermodiffusion coefficient, respectively

take place in the sample. This is due to arising the temperature by the different absorption of light in such places. Verification of above-mentioned considerations has been performed by measurements on the samples of kerosene- and mineral oil-based magnetic liquid with magnetite covered by mono- and double-layer, respectively.

\section{EXPERIMENT}

The structuralization of the magnetic particles concentration was experimentally observed in two types of magnetic fluid: magnetic fluid based on mineral oil with magnetite particles covered by oleic acid as mono-layer surfactant, and kerosene-based magnetic fluid, sterically stabilized by double-layer consisting of oleic acid and dodecylbenzensulphonic acid (DBS) [8]. The used surfactant is anionic [9], thus, according to the observations of Alves et al. [3], the Soret constant of the studied magnetic fluid should be negative and the structuralization of the particle concentration should be observed in the illuminated sample. A thin sample of magnetic fluid (thickness $100 \mu \mathrm{m}$ ) was lighted with a laser beam with $\lambda=488 \mathrm{~nm}$, generated by the Zeiss Ar laser ILA 120 with power $150 \mathrm{~mW}$. The radiant power in the sample was multiplied by a converging lens. The whole process, from the beginning of the heating to the structure development, was photographed from the ground-glass screen and then digitized. The negative value of the Soret constant was also verified by the Forced Rayleigh Scattering experiment, whose set-up consisted of the Zeiss Ar laser, a beam splitter, a mechanical shutter, 
a thin sample of magnetic fluid (thickness $5 \mu \mathrm{m}$ ) and a photo detector connected to PC. The beam splitter gave two coherent beams providing an interference field in the sample. The space period of the interference field was in the range from 5 up $200 \mu \mathrm{m}$.

\section{RESULTS AND DISCUSSION}

In case of the Forced Rayleigh Scattering experiment, a concentration grating was created in the interference field of two coherent laser beams. Figure 3 shows the picture from the ground-glass screen, which illustrates the situation observed in the kerosene-based magnetic fluid. Here, the created concentration grating is shifted according to the interference one, as the particles are attracted to the hot regions (light stripes in the interference grating). For comparison, Fig. 4 shows the situation observed in the magnetic fluid with a positive Soret constant, where both gratings overlap. It is convenient to study the kinetics of nanoparticles using the predetermined structure of the light field. Such a structure may be, for instance, a grating formed by use of two crossed coherent laser beams interfering in places of their intersection. The sample of the colloidal liquid in form of the thin layer (thickness about $60 \mu \mathrm{m}$ ) was inserted into the interference field, and the periodic thermal field was thus formed.
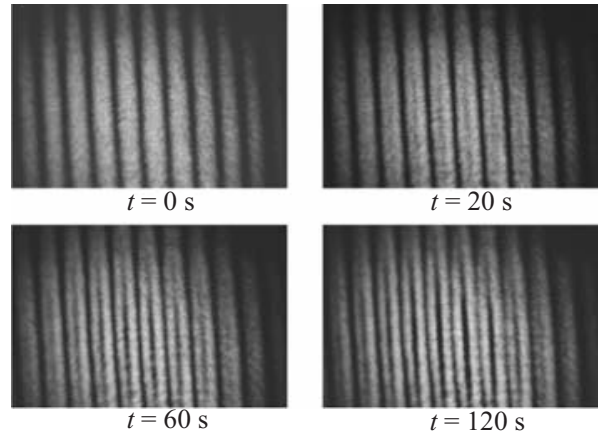

Fig. 3. The shifted interference and concentration gratings in kerosene-based magnetic fluid with $S<0$

Due to the diffusion and thermodiffusion of the nanoparticles the concentration diffraction grating will be created. According to the behaviour of the time dependence of the grating decay (after switching off the interference field and under the presence of the additional lighting), it is possible to determine the sign of the thermo-diffusion coefficient $S$. The additional illumination was realized by a homogeneous Ar laser with power $0.56 \mathrm{~W} \cdot \mathrm{cm}^{-2}$. The grating created in the mineral oil-based magnetic fluid with $S>0$ will decay in the same way 

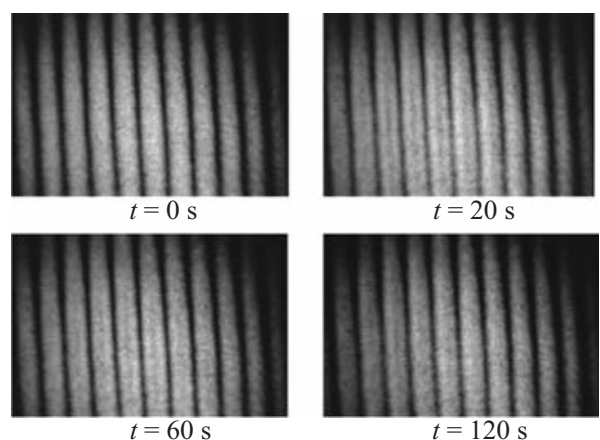

Fig. 4. The overlap of interference and concentration gratings in mineral oil-based magnetic fluid with $S>0$

independently of the fact of its additional illumination (see Fig. 5, $a, b$ ) and the structure will decay $240 \mathrm{~s}$ after the switching off the interference field. Another situation was observed for the kerosene-based magnetic fluid with $S<0$. The grating decay without additional illumination is the same as in case of sample with $S>0$. However, as it can be seen from Fig. 5, $c, d$, the structure decay differs considerably under the presence of the additional illumination, and the grating decay is slower and grating was observed still after $360 \mathrm{~s}$.

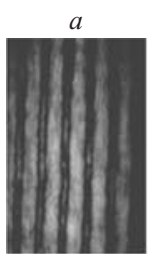

$0 \mathrm{~s}$

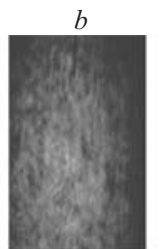

$360 \mathrm{~s}$

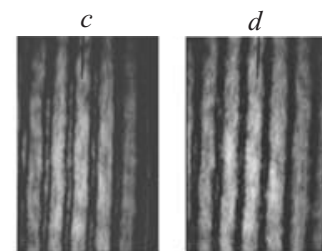

$0 \mathrm{~s}$
$360 \mathrm{~s}$

Fig. 5. The grating decay in kerosene-based magnetic fluid without $(a, b)$ and with $(c, d)$ additional illumination

The time dependence of the grating decay in the kerosene-based magnetic fluid without and with additional illumination can be seen in Figs. 6 and 7, respectively. From these figures it is clear that without additional illumination the structure disappeared completely at $200 \mathrm{~s}$, whereas with illumination the structure is observable up to higher values as an evidence of the negative thermodiffusion constant, too. 


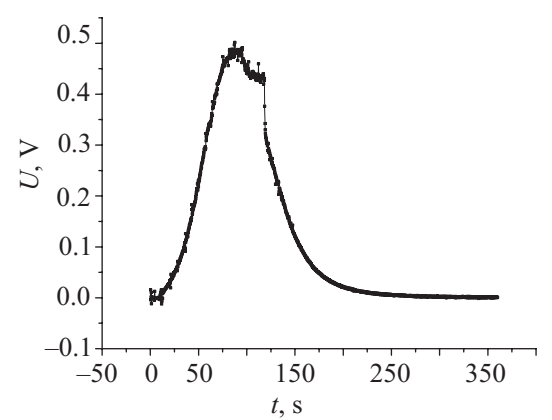

Fig. 6. The time dependence of structure decay in kerosene-based magnetic fluid without additional illumination

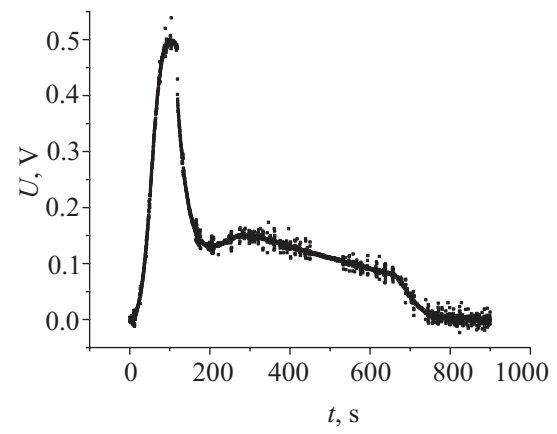

Fig. 7. The time dependence of structure decay in kerosene-based magnetic fluid with additional illumination

\section{CONCLUSIONS}

To conclude it can be said, that the obtained results verified the negative value of the Soret constant in the kerosene-based magnetic fluid. The development of the structuralization of magnetic particles concentration in the illuminated thin sample that after the illumination intensity reaches some critical value $I_{0}^{c}$, was numerically simulated and then verified experimentally. It proved to be convenient to investigate the kinetics of the nanoparticles in the dispersion liquid on the welldefined geometric structure such as the concentration-diffraction grating. From the time dependence of the grating decay it was possible to determine the sign of the thermo-diffusion coefficient $S$.

Acknowledgements. This work was supported by the Science and Technology Assistance Agency (APVT project No. 51-027904) and the Slovak Academy of Sciences (VEGA project No. 6166).

This work was partially supported by grants RFBR 05-01-00645, 06-0100530, 04-01-00490, RFBR-BRFBR 06-01-81014. 


\section{REFERENCES}

1. Völker T., Blums E., Odenbach S. // J. Magn. Magn. Mater. 2002. V. 252. P. 218.

2. Lenglet J., Bourdon A., Bacri J.C., Demouchy G. // Phys. Rev. E. 2002. V.65. P. 031408-1.

3. Alves S., Demouchy G., Bee A., Talbot D., Bourdon A., Figueiredo Neto A. M. // Philo. Mag. 2003. V. 83. P. 2059.

4. Turek I., Štelina J., Musil C. et al. // Magnetohydrodynamics. 2003. V. 39. P. 375.

5. Kopčanský P., Timko M., Potočová I. et al. // J. Magn. Magn. Mater. 2005. V. 289. P. 97.

6. Štelina J., Musil C., Braciník J. // The 10th International Workshop on APCOM, Častá - Píla, Slovakia, 2004. P. 253.

7. Štelina J., Musil C., Braciník J., Kopčanský P., Timko M., Koneracká M. // Proc. of the Intern. Workshop, APCOM, Malá Lučivná, Slovakia, 2005. P. 230.

8. Bica D., Vèkàs L., Rasa M. // J. Magn. Magn. Mater. 2002. V. 252. P. 10.

9. Donselaar L. N., Philipse A.P., Suurmond J. // LANGMUIR. 1997. V. 13, No. 23. P. 6018.

Received on December 29, 2006. 


\section{Редактор В. В. Рудниченко}

Подписано в печать 29.05.2007.

Формат $60 \times 90 / 16$. Бумага офсетная. Печать офсетная.

Усл. печ. л. 0,68. Уч.-изд. л. 0,97. Тираж 430 экз. Заказ № 55787.

Издательский отдел Объединенного института ядерных исследований 141980, г. Дубна, Московская обл., ул. Жолио-Кюри, 6.

E-mail: publish@jinr.ru www.jinr.ru/publish/ 